\title{
A case of apathetic thyrotoxicosis simulating malignant disease
}

\author{
M. J. DoDD* \\ B.Sc., M.B. B.S., M.R.C.P. (U.K.)
}

D. R. BLAKE

M.B. ChB., M.R.C.P. (U.K.)

Department of Medicine, Newcastle General Hospital, Newcastle upon Tyne

\begin{abstract}
Summary
A patient with apathetic hyperthyroidism and who was initially considered to be suffering from malignant disease and progressed to crisis is described. The role of magnesium in this presentation of thyrotoxicosis is discussed.
\end{abstract}

\section{Introduction}

Apathetic thyrotoxicosis is a rare presentation of hyperthyroidism. Lahey (1931a) first drew attention to the thyrotoxic patient in whom the characteristic mental and physical activation of hyperthyroidism was missing and the chief clinical features were exhaustion, weakness, apathy and depression. Severe muscle wasting and loss of weight is usual and, although giving every appearance of apathy, the metabolic effect of the disease is severe and thyrotoxic crisis is in danger of being missed with its consequent fatal outcome (McGee, Whittaker and Tullis, 1959).

A recent report has linked hypomagnesaemia with apathetic thyrotoxicosis and suggested that magnesium deficiency may be a factor in the aetiology of this particular presentation of thyrotoxicosis (Marks and Ashraf, 1978).

The authors wish to report a case of apathetic thyrotoxicosis in a patient who was considered to be suffering from malignant disease and who progressed to crisis after surgery, but who had normal serum magnesium levels.

\section{Case history}

A 39-year-old sheet metal worker was referred for surgical opinion because of a 5-month history of anorexia, $15 \mathrm{~kg}$ weight loss, altered bowel habit with constipation and colicky upper abdominal pain. He had become depressed and withdrawn over the preceding 3 months and, because of his weakness, had been unable to continue with his work.

Examination showed a thin, lethargic man with gross tissue loss and extreme proximal weakness of

* Present address : Department of Rheumatology, Freeman Hospital, Newcastle upon Tyne. the limbs which resulted in difficulty in walking, rising from a chair unaided, and inability to lift his hands above the level of his waist when standing. In the abdomen, a firm, poorly mobile mass could be palpated in the left upper quadrant and, because of the general appearance of the patient, a diagnosis of large bowel carcinoma in the region of the splenic flexture was considered.

In view of the suspected diagnosis, it was decided to proceed straight to laparotomy. However, the only abnormality was a $4-\mathrm{cm}$ diameter, calcified lymph gland in the large bowel mesentery. There was no evidence of active tuberculosis on subsequent histology.

During the operation the anaesthetist recorded the onset of rapid atrial fibrillation, with a ventricular rate of 140 beats/min. Over the next $24 \mathrm{hr}$ the patient developed a pyrexia of $40^{\circ} \mathrm{C}$, together with a mild icterus, increasing agitation, and ultimately delirium.

Although re-examination showed no evidence of exophthalmos or goitre, and the main features were weight loss, a proximal myopathy and inertia, apathetic thyrotoxicosis progressing to storm was considered as a possible diagnosis.

Treatment was begun with digitalis, intravenous propranolol and hydrocortisone and within $24 \mathrm{hr}$ there was noticeable improvement in his general condition and mental state. When the results of his thyroid function were known, treatment was continued with digitalis and propranolol, and oral carbimazole was commenced.

Routine investigations before surgery showed an $\mathrm{Hb}$ of $14.2 \mathrm{~g} / \mathrm{dl}$ with normal indices, normal biochemical profile (Vicker's multichannel analysis), normal chest X-ray and ECG. Twenty-four hours postoperatively his $\mathrm{Hb}$ had fallen to $11.0 \mathrm{~g} / \mathrm{dl}$ with normal indices, WCC $9.7 \times 10^{9} / 1$, aspartate transaminase 43 i.u./l (normal range $<37$ i.u./l), bilirubin $24.7 \mu \mathrm{mol} / 1$ (normal range $<17.0 \mu \mathrm{mol} / \mathrm{l}$ ), calcium $2.34 \mathrm{mmol} / \mathrm{l}$ (normal range $2.25-2.75 \mathrm{mmol} / \mathrm{l}$ ), magnesium $0.86 \mathrm{mmol} / \mathrm{l}$ (normal range $0.70-1.00$ $\mathrm{mmol} / \mathrm{l}$ ), alkaline phosphatase 93 i.u./l (normal range $28-92$ i.u./l), total protein $67 \cdot 7 \mathrm{~g} / \mathrm{l}$ (normal 
range $60-80 \mathrm{~g} / \mathrm{l}$ ), albumin $36.6 \mathrm{~g} / \mathrm{l}$ (normal range 34-50 g/l). Before starting carbimazole, the following thyroid function tests were performed: serum $\mathrm{T}_{4}, 241 \mathrm{mmol} / \mathrm{l}$ (normal range $60-140 \mathrm{mmol} / \mathrm{l}$ ); strongly positive titre of thyroid cytoplasmic antibodies, and a thyroid microsomal titre positive to $1 / 1600$; there was no response of TSH to $200 \mu \mathrm{g}$ of TRH $\left(0^{\prime}=1.4 \mathrm{mu} . / 1,30^{\prime}=1.6 \mathrm{mu} . / 1\right)$.

One month after starting carbimazole he had gained $4 \mathrm{~kg}$ in weight, was in sinus rhythm and his bilirubin and aspartate transaminase were within the normal range; haemoglobin $14.7 \mathrm{~g} / \mathrm{dl}$, serum magnesium $0.84 \mathrm{mmol} / 1$ and alkaline phosphatase 94 i.u./l.

At 3 months there was a further $10 \mathrm{~kg}$ weight gain, and the serum magnesium was $0.90 \mathrm{mmol} / \mathrm{l}$ and alkaline phosphatase 0.89 i.u./l, and he remains well on carbimazole $10 \mathrm{mg}$ daily.

\section{Discussion}

Why some patients with thyrotoxicosis should present with activation and others with apathy is unclear, although Marks and Ashraf (1978) have suggested that hypomagnesaemia may be the cause of the apathetic state. However, the 2 cases which they report are more in keeping with classical thyrotoxicosis as their patients describe symptoms of palpitation, anxiety, heat intolerance and sweating, which are not found with what is generally referred to as apathetic hyperthyroidism (Lahey, 1931a, b).

Low serum magnesium has been documented in classical hyperthyroidism (Jones et al., 1966) and magnesium replacement alone has been said to improve the hyperthyroid state (Neguib, 1963). In addition, balance studies show that magnesium is retained during therapy of hyperthyroidism and there is magnesium loss during thyroid replacement for hypothyroidism. It is also suspected that some of the manifestations of thyroid crisis are due to magnesium deficiency (Jones et al., 1966; Tapley, 1955). Yet, in the present patient, despite marked apathy and thyroid crisis, it was not possible to document low magnesium levels. The authors therefore doubt the role of hypomagnesaemia as an essential component of apathetic thyrotoxicosis and, until more cases of apathy with hyperthyroidism are reported, the role of magnesium in this condition must remain speculative.

The authors wish to emphasize the ability of $c$ apathetic thyrotoxicosis to simulate malignant disease; with the extreme weight loss, muscular $\stackrel{\text { ? }}{+}$ weakness and prominent gastrointestinal complaints, it is easy to see how an occult neoplasm may be $\frac{\overline{\bar{O}}}{\overline{\hat{n}}}$ suspected. Moreover, since thyroid crisis is fre- $\frac{\bar{\sigma}}{\widehat{\Phi}}$ quently lethal (Parker and Lawson, 1973) the im- $\varrho$ portance of diagnosis cannot be overstated. In those patients with apathetic hyperthyroidism, crisis may $\vec{\circ}$ develop undetected, the patients quietly sinking into coma without the rise in temperature, marked $\vec{\omega}$ agitation and toxic psychosis of classical thyroid $\stackrel{\odot}{\circ}$ storm (McGee et al., 1959). The diagnosis of hyper-o thyroidism in the present patient only became 3 . evident following the development of classicalog thyroid storm and its associated organ system dys- $\circ$ function. If this had not been precipitated by G surgery, it is unlikely that the patient would have been successfully treated.

\section{Acknowledgment}

We would like to thank Dr C. Strang, M.D., F.R.C.P., for his permission to report this case.

\section{References}

Jones, J.E., Desper, P.C., Shane, S.R. \& Fink, E.B. (19 Magnesium metabolism in hyperthyroidism and hypthyroidism. Journal of Clinical Investigation, 45, 891 .

LAHEY, F.H. (1931a) Apathetic thyroidism. Annals Surgery, 93, 1026.

LAHEY, F.H. (1931b) Non-activated (apathetic) type of $\frac{2}{(D)}$ hyperthyroidism. New England Journal of Medicine, 204, 747.

McGee, R.R., WhitTaker, R.L. \& Tullis, I.F. (1959)引 Apathetic thyroidism: Review of the literature and report? of four cases. Annals of Internal Medicine, 50, 1418.

MARKS, P. \& Ashraf, H. (1978) Apathetic hyperthyroidism with hypomagnesaemia and raised alkaline phosphatase concentration. British Medical Journal, 1, 821.

Neguib, M.A. (1963) The effect of magnesium on the thyroid. Lancet, i, 1405.

Parker, J.L.W. \& Lawson, D.H. (1973) Death from thyrotoxicosis. Lancet, ii, 894.

TAPLEY, D.F. (1955) Magnesium balance in myxedematous patients treated with triiodothyronine. Bulletin of the음 Johns Hopkins Hospital, 96, 274. 